Revista Espaço do Currículo

ISSN 1983-1579

Doi: 10.22478/ufpb.1983-1579.2019v12n1.38670 http://periodicos.ufpb.br/ojs2/index.php

\title{
GÊNERO E SEXUALIDADE: concepções e discussões acerca da educação
}

\author{
GENDER AND SEXUALITY: conceptions and discussions about education
}

\author{
Samira de Moraes Maia Vigano' \\ Maria Hermínia Lage Fernandes Laffin ${ }^{2}$
}

\begin{abstract}
Resumo: Este artigo apresenta alguns levantamentos realizados para a tese de doutorado em educação. Objetiva-se debater as questões de gênero e sexualidade no que tange ao currículo, as diretrizes e as leis propostas para essas questões, problematizando aspectos que deturpam a função social da escola e se incorporam em propostas como a do Projeto Escola sem Partido. $O$ enfoque metodológico efetiva-se em uma pesquisa bibliográfica respaldada em teóricos e teóricas que debatem as questões de gênero, sexualidade, educação, ideologia de gênero, Escola sem Partido e uma análise documental no que tange as leis e diretrizes que envolvem a educação brasileira (Brasil, 1998, 2012 e 2017). Enfatiza-se o debate em torno do Projeto Escola sem Partido, problematizando a proposta e desvendando a ideologia de gênero. Verificou-se que o Projeto Escola sem Partido tem como base o cerceamento do currículo no que tange as discussões de gênero e sexualidade e que essa proibição resulta em formações homofóbicas e misóginas, fortalecendo um currículo segregador das diferenças.
\end{abstract}

Palavras-chave: Gênero; Sexualidade; Educação; Currículo.

\section{PALAVRAS INICIAIS}

Este artigo apresenta alguns levantamentos realizados para a tese de doutorado em educação, em andamento com previsão de término em março de 2019. A tese tem por objetivo compreender a influência das questões de gênero e sexualidade no processo de escolarização de sujeitos jovens e adultos que hoje se autodeclaram LGBT (lésbicas, gays, bixessuais, transexuais, travestis e transgêneros).

Ao compreender as questões de gênero e sexualidade no processo de escolarização dos sujeitos
Abstract: This article presents some surveys carried out for the doctoral thesis in education. The objective is to discuss gender and sexuality issues with regard to the curriculum, guidelines and laws proposed for these issues, problematizing aspects that distort the social function of the school and are incorporated into proposals such as the Project without School. The methodological approach is based on a bibliographical research supported by theoreticians and theorists who discuss the issues of gender, sexuality, education, gender ideology, the School without Partyand and a documentary analysis regarding the laws and guidelines that involve Brazilian education (Brazil, 1998, 2012 and 2017). It emphasizes the debate around the Project without Party School, problematizing the proposal and unveiling the ideology of gender. It was verified that the Project without Party School is based on the curtailment of the curriculum regarding the discussions of gender and sexuality and that this prohibition results in homophobic and misogynist formations, strengthening a curriculum segregating the differences.

Keywords: Gender; Sexuality; Education; Curriculum.

Ao compreender as questres de gênero e sexualidade no processo de escolarizaça dos sueitos

${ }^{1}$ Doutora em Educação pela Universidade Federal de Santa Catarina e Professora Substituta do Instituto Federal de Santa Catarina. E-mail: <samirammvigano@gmail.com> ORCID: <https://orcid.org/0000-0001-8100-9207>

${ }^{2}$ Doutora em Educação pela Universidade Federal de Santa Catarina e Professora Associado III da Universidade Federal de Santa Catarina. E-mail: <herminialaffin@gmail.com> ORCID: <https://orcid.org/0000-0002-4562-308X>

3 Pesquisa em andamento do doutorado em educação do Programa de Pós-graduação em Educação - PPGE da Universidade Federal de Santa Catarina - UFSC, iniciado em março de 2015, na linha de pesquisa de Ensino e Formação de Educadores - EFE. 
LGBT, intenciono identificar as violências e exclusões vivenciadas pelas pessoas que não se enquadram no padrão binário estipulado culturalmente. Dentre as diversas violações, estão às questões referentes ao currículo e propostas curriculares que tendem a não evidenciar a diversidade sexual e de gênero existente na sociedade.

As diferentes formas de violência que existem e que estruturam as relações sociais podem ser explicadas a partir do entendimento de que a violência é um ato de excesso, que se fortifica no exercício das relações de poder presentes na produção do social. Tal "violência pode ser encarada como tendo procedência sobre qualquer respeito pela inviolabilidade da vida privada" (LOURO, 2000, p. 56). Assim, evidencio a necessidade de fazer um recorte na tese, tendo em vista a escrita desse artigo, objetivando debater as questões de gênero e sexualidade no que tange ao currículo, as diretrizes e as leis propostas para essas questões, problematizando aspectos que deturpam a função social da escola e se incorporam em propostas como a do Projeto Escola sem Partido. A metodologia utilizada terá como base a pesquisa bibliográfica e a análise documental, respaldada em teóricos e teóricas que debatam as questões de gênero e sexualidade e as leis e diretrizes que envolvem a educação brasileira.

Cabe ressaltar que a função social da escola tem como base a socialização aliada ao saber científico, contribuindo na construção de um país com igualdade, humanidade e justiça social. Neste viés, as questões de gênero e sexualidade devem fazer parte do debate de sala de aula, até mesmo porque há uma constante invisibilidade dessas questões no que tange a homossexualidade e a transgeneridade. A ocultação dessas discussões no currículo escolar fortalece o preconceito e a discriminação. Além disso, é preciso ter ciência que a escola se fundamentou em bases heterossexuais, brancas, cristãs e masculinas, o que fez com que qualquer outra pessoa que fuja a essa regra seja vista como estranha.

Desse modo, o objeto de imposição de normas para a doutrinação e o controle dos corpos, dos gêneros e das sexualidades foi o currículo, seja ele o prescrito ou o oculto. O currículo, ao longo da história, mostrou-se objeto de poder e de disseminação de uma cultura, deixando de lado aspectos referentes às questões de gênero e sexualidade, invisibilizando sujeitos e contribuindo para o fortalecimento de uma heteronormatividade. Pensando a partir desses aspectos é

[...] relevante refletir sobre as possibilidades e as impossibilidades que essa cultura coloca para a sexualidade. É relevante refletir sobre os modos como se regulam, se normatizam e se vigiam os sujeitos de diferentes gêneros, raças e classes nas suas formas de experimentar prazeres e desejos; refletir sobre as práticas que tais sujeitos põem em ação para responder a esses desejos, as práticas que acionam para se constituírem como homens e mulheres. (LOURO, 2007, p. 204).

No entanto, aos poucos, essas discussões começaram a tomar forma dentro das propostas curriculares em âmbito nacional, estadual ou municipal, a partir da Constituição Federal (1988) e das principais legislações no âmbito da educação brasileira, tais como: a Lei de Diretrizes e Bases da Educação (LDBEN 9394/1996), os Parâmetros Curriculares Nacionais (PCN - Ensino Fundamental) que trazem os temas transversais e o Plano Nacional de Educação (PNE 10172/2001).

Diversos parâmetros normativos nacionais afirmam o compromisso da educação com a igualdade, recusando discriminações e prejuízos sociais. A Lei de Diretrizes e Bases da Educação Nacional, o Plano Nacional de Direitos Humanos e o Plano Nacional de Educação em Direitos Humanos são emblemáticos a esse respeito. Como efeito desses documentos, as desigualdades injustas passaram a constar como questões sociais nos materiais didático-pedagógicos. (LIONÇO; DINIZ, 2009, p. 10).

De acordo com o PCN no tema transversal de Orientação Sexual, no final da década de 1990, foi 
possível iniciar algumas discussões acerca desses temas, todavia elas tinham ainda um caráter preventivo. Vale ressaltar que o tema transversal de Orientação Sexual não diz respeito ao que atualmente compreende-se por orientação sexual, mas tinha um caráter de orientar por meio de informativo sobre as questões de sexo e sexualidade humana. Além disso, valorizou aspectos das diferentes culturas e o respeito à pluralidade.

[...] Conhecer e valorizar a pluralidade do patrimônio sociocultural brasileiro, bem como aspectos socioculturais de outros povos e nações, posicionando-se contra qualquer discriminação baseada em diferenças culturais, de classe social, de crenças, de sexo, de etnia ou outras características individuais e sociais. (BRASIL, 1998, p. 07).

$\mathrm{Na}$ verdade, aspectos referentes a gênero e sexualidade já começam a aparecer quando se discute Direitos Humanos (1948), onde a relação entre igualdade e equidade apresenta-se como uma necessidade da modernidade. As Diretrizes Nacionais para a Educação em Direitos Humanos de 2012, faz referência a gênero e à orientação sexual e afirmam que todas as pessoas tem direito a uma educação não discriminatória e democrática (BRASIL, 2012, p. 02).

Entretanto, mesmo em meio a leis, decretos ou parâmetros, o currículo educacional ainda se mostra "tímido" em relação ao debate de gênero e sexualidade, mas pode-se dizer que houve avanços em relação à formação docente nesse campo, principalmente a partir de meados dos anos 2000, com o Curso de Gênero e Diversidade na Escola ${ }^{4}$ (Ministério da Educação/MEC, 2006), a criação da Secretaria Especial de Políticas para Mulheres e da Secretaria Especial de Políticas de Promoção da Igualdade Racial, o Programa Brasil sem Homofobia, o Programa de Combate à Violência e à Discriminação contra GLTTB (gays, lésbicas, travestis, transexuais e bissexuais) e com a Promoção da Cidadania Homossexual (2004). Assim, o Ministério da Educação buscou a implementação de políticas públicas em educação com a finalidade de valorizar a diversidade étnico-racial e combater o racismo, promover a equidade de gênero e também, combater todas as formas de discriminação social.

A escola é um espaço sócio cultural onde todas as formações identitárias encontram-se, e por consequência, deve ser o lugar em que se priorize o respeito às diferenças, mas ser diferente incomoda, causa estranhamentos e quanto mais os movimentos em prol da igualdade de gênero se fortalecem e solicitam sua "entrada" nos currículos escolares, mais são vistas ações de cerceamento e violação das identidades tidas como transgressoras, principalmente as que ferem a heterossexualidade. Haja vista a entrada do Movimento Brasil Livre com a bandeira da Escola sem Partido e a nova Base Curricular Comum (BNCC) que retirou a discussão de gênero, destacando as temáticas em torno da diversidade e da sexualidade mais voltada a saúde e reprodução.

Ao tratar na BNCC a temática em torno da diversidade, isso faz com que haja uma redução da complexidade dessas categorias - gênero e sexualidade, deixando todo o conjunto de discussão no mesmo patamar, desconsiderando as violências cotidianamente sofridas por pessoas com diferentes orientações sexuais ou identidades de gênero.

A BNCC traz a temática do corpo no que diz respeito ao cuidado com a saúde e no respeito às diferenças individuais, respeito à diversidade étnico-cultural e à inclusão de alunos e alunas da educação especial (BRASIL, 2017), isso nos anos iniciais da educação básica. Nos anos finais, sugere-se abordar temas relacionados à reprodução e à sexualidade humana (BRASIL, 2017), desconsiderando as questões

${ }^{4}$ O Curso de Gênero e Diversidade na Escola foi ofertado em um projeto piloto em 2006, resultado de uma articulação entre diversos ministérios (Secretaria Especial de Políticas para Mulheres, Secretaria Especial de Políticas de Promoção da Igualdade Racial e o Ministério da Educação), o Conselho Britânico (órgão do Reino Unido atuante na área de Direitos Humanos, Educação e Cultura) e o Centro Latino-Americano em Sexualidade e Direitos Humanos (CLAM/IMS/UERJ). http://portal.mec.gov.br/arquivos/redediversidade/pdfs/gde.pdf 
de gênero, favorecendo as violências. Essa discussão, no Brasil, é particularmente importante já que o país é uma dos que mais mata, violenta e discrimina pessoas LGBT.

Já o Projeto da Escola sem Partido surge dentro de um contexto de ampla disputa no campo político governamental para atender demandas de determinados setores conservadores políticos de preservação da família tradicional brasileira. Dentre suas demandas há o desejo de "calar" os poucos avanços em relação a um currículo que atenda as diversidades, e que seja culturalmente agregador das questões de gênero e sexualidade. A proposta é um retrocesso no pouco que se pode avançar a respeito desses temas. Assim, "esse processo de distinção terá alguma força normativa e, de fato, alguma violência, pois ele pode construir apenas através do apagamento [...]”. (LOURO, 2000, p. 120). Contextualizar como esses processos foram se corporificando através dos tempos é extremamente pertinente para o debate, pois se relaciona às questões curriculares e às demais ações que envolvem o processo de escolarização. Posto isso, considero que a discussão é necessária e relevante, no que diz respeito aos aspectos das leis e o Projeto Escola sem Partido, sobretudo quando se reflete acerca da onda conservadora que assola na atualidade o Brasil e, particularmente o sistema educacional e que leva o nome de ideologia de gênero.

A chamada ideologia de gênero, segundo Junqueira (2017) é uma invenção católica que veio relacionada com os desígnios do Conselho Pontifício para a Família, da Congregação para a Doutrina da Fé, na década de 1990 nos anos 2000. Trata-se de uma retórica reacionária antifeminista e neofundamentalista católica, contrária inclusive a disposições do Concílio Vaticano II. O termo ideologia de gênero não corresponde ou resulta dos estudos de gênero ou de movimentos sociais, ele é um termo de origem vaticana, que se fomenta por uma agenda ultraconservadora, antifeminista e antagônica à democracia e aos direitos humanos entendidos em bases mais amplas e plurais (JUNQUEIRA, 2017). Entende-se por uma ideologia um corpo fechado de ideias, que parte de um pressuposto básico de ser falsa, com o desejo de se impor sobre algo, evitando uma análise racional (SCALA, 2012).

É importante frisar que nenhum dos planos, leis ou propostas voltadas para a educação brasileira falam sobre ideologia de gênero, todavia esse termo cunhou-se como sendo um processo de doutrinação realizado nas escolas sobre as questões de gênero e sexualidade. Assim, fica cada vez mais difícil pautar sobre gênero e sexualidade nas escolas, principalmente depois que setores conservadores da sociedade assumiram uma postura mediante a chave analítica equivocada intitulada de ideologia de gênero.

\section{PROJETO ESCOLA SEM PARTIDO}

Em uma atual conjuntura social marcada por ideias e teorias de alinhamento ao pensamento da direita e às diretrizes de condução neoliberais, frente a um enfraquecimento sistematizado do plano político de partidos alinhados à ideologia da esquerda e a volta da repressão aos movimentos da sociedade civil, surge o Projeto Escola sem Partido, como forte tentativa de coibir uma suposta doutrinação de cunho político esquerdista na educação brasileira.

O MBL (Movimento Brasil Livre) é o movimento que lidera o Escola sem Partido. Ele surgiu ao final de 2014 com as manifestações decorrentes dos estados de São Paulo e do Rio Grande do Sul, combinando forças com as bancadas ${ }^{5}$ evangélica e ruralista do congresso nacional. Em sua agenda para além do Escola sem Partido, estão em pautas políticas de estado mínimo, a reforma trabalhista, o ajuste fiscal e redução da maioridade penal ${ }^{6}$, todos projetos de âmbito nacional.

\footnotetext{
5 Bancadas formadas por deputados que são evangélicos ou do agronegócio. A bancada da bala tem 272 parlamentares, sendo a ruralista com 198, e a evangélica com 74. Apelidada de bancada BBB em referência a boi, bala e bíblia, é uma das bancadas mais conservadoras dos últimos anos.

${ }^{6}$ Todas essas propostas desejam conter os avanços realizados por meio das lutas de classes e dos movimentos sociais em prol dos direitos das minorias.
} 
Nesse contexto intermediado por perspectivas decorrentes do MBL a educação brasileira se cercou de vários projetos de lei que desejam mudanças ou retrocessos no âmbito educacional. Esses projetos estão fortemente vinculados com essa bancada religiosa, (FURLANI, 2016) formada por deputados e senadores, que tem poder de votar no congresso nacional, e decidir o "destino" de vários setores, inclusive da educação. Há então, uma mistura de política e religião que vem descaracterizar a laicidade no Brasil, e que deseja a manutenção de uma família nos moldes patriarcais, como pode ser visto no discurso do político Marcelo Bezerra Crivella, religioso brasileiro prefeito do Rio de Janeiro (Mandato inicial 2017-2021),

Essas coisas tem um valor sagrado. Essas coisas são caras a nós, cujas tradições, princípios e valores são os da família. Daquela família 'adâmica': um homem, uma mulher e seus filhos. E agora com essa discussão de ideologia de gênero nós ficamos sujeitos a deformações, que amanhã poderão ter reflexos muito complexos até de serem avaliados, porque vai dar uma confusão no futuro. $\mathrm{E}$ pior, desautoriza o pai e a mãe na sua autoridade de educador. (CRIVELLA, 2015 apud BIROLI, 2015, s/p, grifos nossos).

Sendo assim, aparecem fortemente algumas políticas inquisitórias marcadas por um retrocesso, tendo em vista a não ampliação ou a finalização dos Direitos Humanos, principalmente na incorporação das políticas públicas em relação à classe, gênero, sexualidade, deficiências, raça e etnia, tendo como objetivo o cerceamento de um currículo que vise atender as diversidades.

Dentre os projetos encabeçados para vigorar dentro do que propõe o Escola sem Partido há o Projeto de Lei - PL 867/2015, apresentado pelo deputado Izalci Lucas Ferreira (PSDB) e coadunado na PL 7180/2014 que deseja incluir nas Diretrizes e Bases da Educação Nacional (DCN), o Projeto Escola sem Partido. O MBL também tem como meta incluir sua proposta na LDBEN (Lei de Diretrizes e Bases e Educação Nacional), determinando princípios educativos ditos como neutros, e delimitando o comportamento e os deveres docentes a favor de uma neutralidade ideológica, política e partidária?. Para quem vê essa proposta sem entrar nas entrelinhas entende sendo algo interessante para a educação, já que, a proposta deseja que a sala de aula seja um lugar com princípios de neutralidade ideológica, política e partidária, todavia, esses princípios indicados pela Escola sem Partido acobertam o que de fato eles querem atingir.

É importante também atentar ao Projeto de Lei - PL 2731/2015 de autoria do deputado federal Eros Biondini (PTB-MG) que defende a inclusão do seguinte trecho no artigo $2^{\circ}$ do PNE - Plano Nacional de Educação: “É proibida a utilização de qualquer tipo de ideologia na educação nacional, em especial o uso da ideologia de gênero, orientação sexual, identidade de gênero e seus derivados, sob qualquer pretexto"8. Aqui, nesse PL é perceptível os objetivos aos quais a Escola sem Partido, encabeçado pelo Movimento Brasil Livre intenciona: a punição de professores ou de professoras que falem de gênero ou sexualidade em sala de aula, podendo estar sujeitos às mesmas penas previstas no artigo 232 do

\footnotetext{
7 Segundo a análise feita no site do Programa Escola Sem Partido levantada no período de janeiro a março de 2017 , os professores e as professoras (principalmente as feministas) formam um exército de militantes em favor da “doutrinação marxista, esquerdista". Entre os/as apoiadores e apoiadoras deste movimento está o Movimento Brasil Livre (MBL), um dos protagonistas dos protestos pelo impedimento da então Presidenta Dilma Rousseff, deputados do PSC, PMDB e PSDB, a bancada evangélica, professores universitários como Bráulio Porto de Matos, vice-presidente desse movimento e professor da Faculdade de Educação da Universidade de Brasília e atores como Alexandre Frota, ambos levaram a proposta da Escola Sem Partido para o Ministro da Educação, Mendonça Filho, e foram muito bem recebidos e acolhidos (GADOTTI, 2016).

8 Declarações realizadas na mídia online e veiculadas no site: $<$ http://educacaointegral.org.br/reportagens/projeto-de-lei-preve-prisao-de-docente-que-falar-sobre-ideologia-de-g enero/>
} 
Estatuto da Criança e do Adolescente (ECA), que prevê prisão de 6 meses a 2 anos. Tornam-se mais visíveis essas intenções quando em outro texto que tramita no congresso nacional, de autoria do deputado Erivelton Santana (PSC-BA) denominado de Projeto de Lei - PL 7180/2014, que também pretende alterar a Lei de Diretrizes e Bases (LDBEN 9394/96), no que se refere aos temas transversais, pois segundo o deputado, eles são um marco da inculcação da ideologia de gênero na escola.

Em Assembleias Legislativas e Câmaras de Vereadores, esses grupos vêm atuando para eliminar das diretrizes educacionais orientações para a valorização e respeito à diversidade sexual e para a superação das desigualdades de gênero. A própria palavra "gênero" vem sendo sistematicamente eliminada nos casos em que essa empreitada teve sucesso. (BIROLI, 2015, s/p).

Dentre os vários projetos, a polêmica, pelo que percebi, está no que no debate sobre gênero em sala de aula, denominado pelo movimento de ideologia de gênero. Desse modo, vale novamente trazer ao debate esse termo, a fim de problematizar como essa temática pretende desmantelar as bases curriculares da educação do Brasil.

O termo ideologia de gênero não está presente e não é de uso das teorias de gênero. Essa expressão foi criada ou inventada por um fundamentalismo religioso que buscou cunhar uma compreensão equivocada do que é gênero, enfatizando que os estudos de gênero na escola podem fazer com que haja uma doutrinação de valores homossexuais ou transexuais na "mente" dos alunos ou das alunas (FURLANI, 2016). Compreendo que ao utilizarem o termo ideologia para se referirem aos estudos de gênero estão dizendo que há um processo de "doutrina mais ou menos destituída de validade objetiva, porém mantida pelos interesses claros ou ocultos daqueles que a utilizam" (ABBAGNANO, 2003, p. 521), ou seja, que os estudos de gênero desejam uma doutrinação ideológica, por isso, devem ser chamados de ideologia de gênero. A partir desse esclarecimento começo a refletir sobre o que há por trás da chamada ideologia de gênero e como isso afeta o que já foi construído junto aos Direitos Humanos e nos processos curriculares.

Sendo assim início com a citação de Biroli (2015) que diz que:

A democracia e os direitos individuais estão sendo ameaçados por ofensivas contra o que vem sendo chamado de "ideologia de gênero". Trata-se da ação retrógrada, orquestrada, de alguns grupos religiosos na política. Embora se digam contra uma "ideologia", atuam para frear e interromper a consolidação de valores básicos da democracia, como o tratamento igual aos indivíduos independentemente do que os singulariza e a promoção, no ambiente escolar, do respeito à pluralidade e diversidade que caracterizam as sociedades contemporâneas. (BIROLI, 2015, s/p).

Percebo, então, que isto que chamam de ideologia de gênero é de decorrente da falta de compreensão e aceitação das propostas trazidas a partir dos estudos de gênero e de nada se relaciona com o que objetiva esses estudos. Os estudos de gênero objetivam a busca do respeito, da equidade e da aceitação de todas as diversidades. O uso do termo ideologia de gênero deseja constituir uma imagem negativa dos estudos de gênero, embutido no imaginário de várias pessoas que se as professoras e professores falarem de gênero em sala de aula, estarão ensinando seus filhos e filhas a serem homossexuais ou a alterarem sua identidade de gênero. Essa falta de entendimento levou muitas famílias a solicitarem aos congressistas a retirada "do gênero" do discurso docente. Essa não compreensão é proveniente da ideia de que:

[...] Quanto menos os/as alunos/as souberem sobre gênero e à sexualidade, tanto mais estarão protegidos em relação a eles. O pressuposto é que o conhecimento, nesse caso é nocivo. Outra associação possível é a de que tais 
temas seriam unicamente de caráter íntimo e privado, não tendo nada a ver com a esfera social - o que já foi problematizado há muito, pelo movimento feminista ao afirmar que o pessoal é político. (BALESTRIN; SOARES, 2015, p. 49).

A intromissão na autonomia da escola é tanta que, de acordo com o Projeto Escola sem Partido, tornar-se-á obrigatória à colocação de cartazes em todas as salas de aula do ensino fundamental e médio contendo os "deveres do professor" 9. São 6 (seis) deveres contra o abuso da liberdade de ensinar, dos quais trarei apenas alguns aqui para o debate (deveres I, III e V) para ilustrar e levar a uma reflexão própria: dever I - O Professor não se aproveitará da audiência cativa dos alunos, para promover os seus próprios interesses, opiniões, concepções ou preferências ideológicas, religiosas, morais, políticas e partidárias [...]; dever III - O Professor não fará propaganda político-partidária em sala de aula nem incitará seus alunos a participar de manifestações, atos públicos e passeatas [...] e dever $\mathrm{V}$ - $\mathrm{O}$ Professor respeitará o direito dos pais dos alunos a que seus filhos recebam a educação religiosa e moral que esteja de acordo com suas próprias convicções [...] (retirado do site do Programa Escola sem Partido, sem referência de autoria e sem página).

Tal postura é extremamente contraditória, pois impõe sim uma determinada ideologia, que é a de controle humano e de implementação de uma visão política partidária conservadora. Esse movimento vem gerando ataques de discurso de ódio ao magistério e afrontam a liberdade de cátedra docente. São exemplos disso, a incitação aos alunos e pais via redes sociais, por parte de representantes do movimento conservador, a afrontarem seus professores e professoras a gravarem suas aulas com o objetivo de controle e de denúncia quando perceberem de que os docentes estariam tratando de conteúdos que se referissem à análises de caráter social e às questões dos direitos sociais e de gênero. Tal incitação se justificaria na visão do movimento conservador, pois tais práticas se encaixariam na suposta e equivocada visão que haveria uma doutrinação política de esquerda. A partir do exposto, concordo com Cara (2016) quando retrata que:

Sob o véu da pluralidade declarada o que se observa é a promoção de um perigoso dogmatismo conservador. Os projetos de lei da Escola Sem Partido se baseiam na acusação de que há uma doutrinação moral e ideológica de esquerda nas escolas brasileiras. Diante disso, os professores devem ser vigiados e controlados no exercício de sua profissão, por meio da imposição de limites à liberdade de cátedra - um dos pilares fundamentais do magistério. (CARA, 2016, p. 44).

Em contraposição a esses "deveres do professor", Biroli (2015), indica a importância de uma educação para a igualdade e para a compreensão das diversidades. Sendo assim, a práxis pedagógica pode orientar para atuação de professores e professoras, que contribuam para a diminuição do sofrimento dos indivíduos que veem o valor das suas vidas reduzido por questões de gênero, onde, as meninas estão sujeitas a estupro e abusos, e sujeitos são diariamente agredidos em razão de sua identidade de gênero ou orientação sexual, favorecendo assim uma formação para transformação social, objetivando a construção de relações mais respeitosas dentro de uma sociedade mais igualitária (BIROLI, 2015). Além disso,

Dialogar sobre gênero no contexto escolar implica, na maioria das vezes, debater sobre diferentes posições, conceitos, concepções, opinião sobre o que esperamos de cada gênero. É um exercício que exige conhecimento teórico-metodológico sobre a temática para que possam ser identificados os argumentos pautados em concepções conservadoras, machistas, sexistas,

\footnotetext{
${ }^{9}$ Aqui só trarei os termos no masculino, pois é assim que o site se direciona.
} 
GÊNERO E SEXUALIDADE: concepções e discussões acerca da educaçãoVIGANO, S. M. M.; LAFFIN, M. H. L. F.

homofóbicas, heterossexistas, racistas, classistas, etc. (GRAUPE; SOUSA, 2015, p.113).

É importante ainda destacar que o site do Escola sem Partido possui uma área determinada para que as pessoas façam denúncias sobre práticas docentes "duvidosas" ". A página aberta a todos e todas na internet expõe que, quando a família perceber que seus entes estão sendo vítimas de doutrinação ideológica, ou seja, de ideologia de gênero, a denúncia deve ser feita, para que o MBL tome as devidas providências, que são: perseguição dos professores e professoras em redes sociais, no espaço de trabalho ou de residência, faixas acusatórias em locais públicos para desmoralizar o professor ou professora, até registro de Boletim de Ocorrência (BO) com acusação de assédio moral ou violação do Estatuto da Criança e Adolescente (ECA).

São vários os projetos de lei que visam modificar a legislação curricular brasileira para instituir a censura, proibir a livre manifestação do pensamento e criminalizar o professorado. Alguns projetos de lei são mais locais (PL municipais) como a Lei da Mordaça (PL 01/2015), da deputada distrital Sandra Faraj (Partido SD - Solidariedade), e outros mais, que se forem concretizados trarão um retrocesso em décadas, do que pouco se conquistou nos últimos anos.

Essas manifestações e projetos colocam-se como defensores de uma escola difusora de um conhecimento neutro e equilibrado, funcionando sem correntes políticas ou ideológicas, todavia, torna-se evidente ao navegar pelo site e pelos projetos de lei, que o movimento está vinculado a forças reacionárias, que se instauraram, buscando remodelar políticas nacionais, dentre outras pretensões. Tais relações retiram do estado a laicidade conquistada, e atribui uma nova roupagem para a interferência religiosa, não sendo mais os eclesiásticos da igreja católica que interferem diretamente no currículo, mas sim os deputados pastores.

Desse modo, mesmo que:

[...] no Estado laico, marcado pela separação entre Estado e religião, todas as religiões mereçam igual consideração e profundo respeito, inexistindo, contudo, qualquer religião oficial, que se transforme na única concepção estatal, a abolir a dinâmica de uma sociedade aberta, livre, diversa e plural. Há o dever do Estado em garantir as condições de igual liberdade religiosa e moral, em um contexto desafiador em que, se de um lado o Estado contemporâneo busca separar-se da religião, esta, por sua vez, busca adentrar nos domínios do Estado (ex: bancadas religiosas no Legislativo). (PIOVESAN, 2006, p. 16).

Vale enfatizar que essa referência ao fundamentalismo religioso relaciona-se com o movimento religioso e conservador surgido nos Estados Unidos no início do século XX, pelos seguidores do protestantismo, em que o objetivo central era de inserir as palavras bíblicas como fundamentais para guiar a vida dos seres humanos. Na atualidade, esse fundamentalismo veio à tona também com o fortalecimento da bancada de deputados cristãos no Congresso Nacional Brasileiro, os quais se uniram a outros deputados da esfera conservadora, a fim de incutir "velhos" princípios conservadores que delimitam o lugar das mulheres, dos homens, dos negros, dos pobres e dos homossexuais (FURLANI, 2016).

O comportamento aprendido culturalmente no Brasil se pautou em padrões europeus, favorecendo a manutenção de um currículo escolar sexista, reprodutor de parâmetros sociais masculinos, heterossexuais e brancos; bem como, a religião judaico cristã, que similarmente, contribuiu para disseminação de uma cultura homogênea, definindo que os que não correspondessem aos padrões, eram pecadores. A escola, assim como as demais instituições sociais, fez parte dessa construção, e ela ainda está permeada por relações de dominação, opressão e poder explicitamente apresentadas nas formulações curriculares, o que faz com que o Projeto Escola sem Partido se

\footnotetext{
${ }^{10}$ Forma pejorativa de como o site direciona-se a essas práticas docentes.
} 
fortaleça.

\section{REFLEXÕES ACERCA DO CURRÍCULO E DAS DIVERSIDADES}

Atualmente os movimentos como o da Escola sem Partido tomam força nas interlocuções políticas e sociais, vejo com isso, uma quebra dos Direitos Humanos básicos, além disso, há uma desconstrução da autonomia docente que colabora ainda mais com a fabricação das diferenças, na ocultação das identidades em cima de normas regulatórias.

Os fatos estão todos os dias nos jornais, em blogs e outras redes sociais. Por exemplo: em Curitiba, a professora de Sociologia Gabriela Viola foi suspensa porque seus alunos e alunas fizeram uma paródia de funk com conceitos marxistas ${ }^{11}$. O professor Paulo César Ramos, de Indaiatuba (SP), foi demitido porque defendeu Lula (ex-presidente do Brasil Luís Inácio Lula da Silva - Partido dos Trabalhadores) no Facebook (rede social). O professor de Biologia, Deneir de Jesus Meireles, de Ceilândia (DF), propôs um projeto sobre gênero e sexualidade e foi notificado pela deputada Sandra (DF), a pedido dos pais de uma aluna (GADOTTI, 2016). Além disso, há a propaganda disseminada no site da frase "meus filhos, minhas regras" (fazendo uma referência à frase usada no movimento de igualdade de gênero "meu corpo, minhas regras"). Entretanto, há resistências e formas de disputas provenientes de Secretarias de Educação, da Ordem dos Advogados do Brasil (OAB), de sindicatos e do Ministério Público.

Ao trazer a tona essas denúncias que fazem apenas fomentar a tradição do patriarcado, onde "o gênero, a família e o território domiciliar contêm hierarquias, nas quais os homens figuram como dominadores-exploradores e as crianças como os dominados-explorados". (SAFFIOTI, 2015, p. 78).

Vale aqui a reflexão sobre para quem o currículo é útil e o que de fato é considerado uma imoralidade na educação, e também compreender que com o projeto de lei (867/2015) sancionado, o Brasil estabelecerá um paradoxo: sob a vigência de uma Escola sem Partido que "emergirá uma escola sem voz, sem liberdade, sem divergências, sem cidadania, sem questionamento, sem reflexão, sem política, sem economia, sem artes, sem apropriação de cultura, ou seja, uma escola sem educação". (CARA, 2016, p. 47).

Com a onda do Movimento Brasil Livre juntamente com o Escola sem Partido tão acirrada no Brasil nos últimos anos (desde 2014 até a presente data dessa escrita - 2018), essa caminhada a favor da equidade tornou-se ainda mais dificultosa. Historicamente amparada em uma cultura que não compreende e tampouco aceita as diversidades de gênero, culminando em uma formação escolar que em vezes objetiva catequizar seus alunos e suas alunas, mostrando-lhes que "é pecado" não seguir os padrões que "Deus" fez de homem e de mulher; levando a escola a um espaço em que:

[...] rotineiramente circulam preconceitos que colocam em movimento discriminações de diversas ordens: classismo, racismo, sexismo, heterossexismo, homofobia e outras formas de gestão das fronteiras da normalidade fazem parte da cotidianidade escolar. Não são elementos intrusos e sorrateiros, que, além de terem entrada franca, agem como elementos estruturantes do espaço escolar, onde são cotidiana e sistematicamente consentidos, cultivados e ensinados, produzindo efeitos sobre todos/as. (JUNQUEIRA, 2012, p. 66).

Desse modo, pelo direito à educação, entendo que uma escola deva tomar partido. Uma escola

\footnotetext{
${ }^{11}$ Marxismo é a corrente teórica e filosófica baseada nos estudos de Karl Marx. É uma forma de analisar as relações de classe e de conflito social baseada no contexto econômico instaurado com o capitalismo, utiliza-se uma interpretação do materialismo histórico e dialético.
} 
que tenha partido é para Paulo Freire uma escola que considere a educação popular como fonte de produção do conhecimento carregado de intencionalidade, ou seja, a educação como um ato político (FREIRE, 1996), sem opressões.

Freire (1996) toma como referência vários aspectos de opressão, e não apenas opressão racial como forma de exclusão, mas todas as demais opressões seja sexual ou de gênero. Ele faz sua denúncia sobre as formas de opressão social que estão em conformidade com a manutenção de sujeitos não pensantes (FREIRE, 1997) que por alguns anos fomentou o currículo brasileiro. No entanto, “o ideal é que na experiência educativa, educandos e educadores, juntos, convivam de tal maneira com este como com outros saberes de que te falarei que eles vão virando sabedoria". (FREIRE, 1996, p. 62).

Talvez a violação do direito à educação para alguns grupos dê-se de forma intencional, mascarada por uma neutralidade fictícia e danosa. Talvez o "medo" de um currículo conscientizador e crítico esteja no fato levantado pela teórica Ivanilde de Oliveira (2013), que diagnosticou que na obra Pedagogia da Esperança, de Paulo Freire, há "a unidade na diversidade constitui a resposta dos oprimidos à regra dividir para reinar da classe dominante. Para ele, sem a unidade na diversidade não tem como as minorias lutarem pelos seus direitos e superarem as suas situações de opressões". (OLIVEIRA, 2013, p. 12).

Outra hipótese pode ser também que o "medo" seja porque receiem que as professoras e professores possam apresentar às alunas e aos alunos as verdades históricas não trazidas nos livros didáticos, conforme salienta Freire:

Os colonialistas diziam que somente eles tinham cultura. Diziam que antes da sua chegada à África nós não tínhamos História. Que a nossa História começou com a sua vinda. Estas afirmações são falsas e mentirosas. Eram afirmações necessárias à prática espoliadora que exerciam sobre nós. Para prolongar ao máximo a nossa exploração econômica, eles precisavam tentar a destruição da nossa identidade cultural, negando a nossa cultura, a nossa História. Todos os povos têm cultura, porque trabalham, porque transformam o mundo e, ao transformá-lo, se transformam. A dança do Povo é cultura. A música do Povo é cultura, como cultura é também a forma como o Povo cultiva a terra. Cultura é também a maneira que o Povo tem de andar, de sorrir, de falar, de cantar, enquanto trabalha. (FREIRE, 1982, p.83-84).

De fato, como afirma Saffioti (2015), não há neutralidade em nenhuma ciência, absolutamente todas são frutos de momentos históricos que se constituem por diversas conjunturas, mas isso não é evidente para qualquer olhar, apenas para o olhar crítico e essa é a função social da escola. Incorporar-se por meio de um currículo crítico reflexivo e acolhedor de todas as culturas e diversidades. Mas o que ocorre, de acordo com Arroyo (2012), é que a história da educação para o povo gira em torno do binômio: permitir sua instrução e reprimir sua educação-formação. No contexto da Escola sem Partido, este binômio ganha fôlego e favorece a manutenção das desigualdades de gênero e a inserção compulsória da heterossexualidade.

Segundo Freire (1982) o mito da neutralidade da educação é

[...] que leva à negação da natureza política do processo educativo e a tomá-lo como um que fazer puro, em que nos engajamos a serviço da humanidade entendida como uma abstração é o ponto de partida para compreendermos as diferenças fundamentais entre uma prática ingênua, uma prática "astuta" e outra crítica. (FREIRE, 1982, p.14).

Em outras palavras, o projeto de lei vinculado ao Escola sem Partido é uma tentativa de conter os avanços das classes populares e das diversidades. As postagens e os sites demonstram "que os defensores dos projetos de lei desejam uma educação moral ultrapassada, completamente 
descontextualizada do mundo e incapaz de refletir a diversidade existente na sociedade brasileira" (CARA, 2016, p. 45). Saliento também que, o professor ou a professora não tem o poder de alterar a orientação sexual ou a identidade de gênero dos sujeitos. A sala de aula é um espaço para a quebra desses preconceitos, e é isso que conduz os estudos de gênero, sexualidade e das diversidades.

Nesse contexto, é importante pensarmos: que tipo de escola temos e que tipo de escola queremos? Que sujeitos temos e que sujeitos queremos? Isso porque a escola, sendo um espaço privilegiado e importante na formação e transformação do sujeito, tem por função, além da transmissão de conteúdo, ampliar o conhecimento de todos/os os/as envolvidos/as na educação. A escola não pode negar-se à reflexão e discussão de situações do cotidiano, dentre elas as desigualdades de gênero e a diversidade sexual, e necessita estar aberta a ouvir a demanda de alunos/as e professores/as. (GRAUPE; SOUSA, 2015, p.113).

A função social da escola está diretamente ligada ao currículo, e o currículo, de acordo com Giroux (1986), tem a função de levar a escola a exercer seu papel como uma esfera pública democrática, em que os alunos e alunas sejam levados a participarem de atividades emancipadoras e críticas. Por meio dessas atividades emancipatórias, tanto os professores e professoras, alunos e alunas, devem ser guiados a questionarem ativamente todas as práticas e conteúdos previamente determinados, e assim, negociarem a relação entre a teoria e a prática, "entre a análise crítica e o senso comum e entre a aprendizagem e a transformação social”. (GIROUX, 2005, p.135).

Por fim, mesmo com o crescimento dos preconceitos e das violências de gênero seja ela contra as mulheres, homossexuais ou pessoas de gênero divergentes ${ }^{12}$, o Escola sem Partido deseja acabar com as discussões de gênero na escola, o fortalecimento e a falta de debate em sala de aula faz com que essas discriminações tenham um efeito limitador "não apenas com relação às possibilidades de inclusão efetiva dos sujeitos no ambiente escolar, mas afetam também as possibilidades de aprendizado". (MOTTA, 2006, p. 53). Todavia, também percebo que esse projeto só se fortaleceu porque ainda exista uma escola permeada por relações de poder, que não apenas reproduzem as desigualdades de gênero, classe, raça ou etnia, mas também se produzem relações hierárquicas, as quais são evidenciadas na organização de um currículo monocultural que gera e provoca a invisibilidade dos sujeitos, particularmente os/as alunos e alunas lésbicas, gays, bissexuais, transexuais ou travestis - LGBT que não se enquadram nos padrões e normas que a escola perpetua.

\section{CONSIDERAÇÕES FINAIS}

Entendo que a negação do direito à pluralidade, seja ela qual for, é uma violação, e isso é o que propõe o projeto da Escola sem Partido. Esse projeto detém-se em formar "uma escola sem pluralidade, sem liberdade, sem diversidade, sem inclusão, sem democracia; uma escola que segrega, que discrimina, que reprime" (GADOTTI, 2016, s/p), ou seja, sem garantia de dignidade e consequentemente, negando um dos Direitos Humanos. Caso haja a implementação do Projeto Escola sem Partido, o Brasil vai caminhar na direção oposta à universalidade na educação, na contramão de uma educação reflexiva e crítica, cidadã e plural (GADOTTI, 2016).

É importante salientar que o trabalho com as diversidades está relacionado com os princípios da inclusão em geral, e não apenas com as questões referentes a gênero e sexualidade. Todavia, pensar em diversidade é direcionar o olhar para as pessoas que estão em busca de seu reconhecimento enquanto sujeitos sociais de direito. De acordo com Graupe e Sousa (2015), o entendimento no debate das diversidades na educação, propicia uma compreensão de que a igualdade social que leva em questão as

\footnotetext{
12 Entendo por identidade de gênero divergente, os indivíduos que não se enquadram, ou se reconhecem no padrão binário, como pessoas travestis, transexuais ou transgêneras - TTT. Segundo Lanz (2015) as pessoas trans ou transgêneras podem ser englobadas no guarda-chuva de gêneros divergentes.
} 
diferenças entre os sexos, classes sociais, gêneros raças e etnias, buscando debater o surgimento das discriminações, a fim do favorecimento à igualdade.

Mesmo com os documentos e leis que falam sobre a importância de pautar um currículo que traga as questões de gênero e sexualidade, ainda há, pela escola uma aceitação limitada ou disfarçada, fazendo com que se fortaleça a propagação do projeto da Escola sem Partido, baseado no senso comum de que existe uma ideologia de gênero.

A proibição ou a ocultação do debate sobre gênero é basicamente a manutenção de certos limites sociais e morais de valores cunhados em uma família tradicional patriarcal, sugerido por alguns grupos que acreditam que estas questões podem ter cunho de doutrinação ideológica. O objetivo por traz do que se diz uma doutrinação, é deslegitimar o potencial crítico e emancipador do feminismo e dos estudos de gênero, permitindo que setores tradicionais e conservadores recuperem seu capital social e político, ameaçado pelas transformações das relações de gênero e sexualidade (JUNQUEIRA, 2017).

Sendo assim, o que há não é uma ideologia de gênero, mas uma ideologia por trás de um movimento que se diz apartidário, fazendo com que professores e professoras sejam alvo de denúncias, demissões e ameaças por falarem de gênero em sala de aula, e isso é pouco dimensionado na mídia. Essa imposição e violência com a profissão docente faz com que haja um impedimento no debate sobre o tema, resultando em futuras formações homofóbicas e misóginas e o fortalecimento de um currículo real e um oculto segregador das diferenças.

Compreendo que "discriminar nada mais é do que uma tentativa de se reduzirem as perspectivas de uns em benefício de outros" (GOMES, 2001, p. 11), ou seja, "quanto mais intensa a discriminação e mais poderosos os mecanismos inerciais que impedem o seu combate, mais ampla se mostra a clivagem entre discriminador e discriminado." (GOMES, 2001, p. 11).

Falar da escola como um espaço de diversidades é sem dúvida adentrar em questões imbricadas na cultura e que consequentemente apresentam-se no currículo. Mesmo que a escola seja um espaço educativo onde circulam pessoas de todas as raças, etnias, gêneros, religiões e classes sociais, ela ainda não é um lugar que atende as demandas das diversidades. Mesmo mediante tantos esforços para desconstruir padrões sexistas, homofóbicos e machistas o que ainda precisa ser feito para que efetivamente haja uma igualdade dentro dos espaços educativos? O currículo de fato agrega todos e todas? Estas são perguntas que permeiam as discussões de gênero nos currículos e nos planos de educação. Há nesse debate um jogo de forças que desejam manter a ótica excludente nas escolas, legitimando currículos que ratificam uma sociedade que exclui o "diferente", e retirando temáticas que fazem parte da construção das identidades de todos os sujeitos.

Sendo assim, entendo que a proposta levantada pelo Projeto Escola sem Partido é uma violência contra um currículo que deve ser emancipador e debater as questões de gênero e sexualidade, e que a falta do debate dessas questões na BNCC limita as ações docentes e se instaura como um mecanismo de controle, uma aceitação reguladora.

\section{REFERÊNCIAS}

ABBAGNANO, Nicola. Dicionário de filosofia. São Paulo: Martins Fontes, 2003.

ARROYO, Miguel Gonzales. Políticas educacionais e desigualdades: à procura de novos significados. V.31, $n^{\circ}$ 113. Educação e Sociedade. Campinas. 2012.

BALESTRIN, P.; SOARES, R. Gênero na sexualidade nas práticas educativas. Retratos da Escola, Brasília, v. 9, n. 16, p. 47-61, jan-jun/2015. Disponível em:

http://www.esforce.org.br/index.php/semestral/article/view/483/596. Acesso em: 5 dez. 2016.

BIROLI, Flávia. A “Ideologia de gênero" e as ameaças à democracia. Blog da Boitempo, 2015. Disponível 
ISSN 1983-1579

Doi: $10.22478 /$ ufpb.1983-1579.2019v12n1.38670

http://periodicos.ufpb.br/ojsz/index.php

em:

<https://blogdaboitempo.com.br/2015/06/26/a-ideologia-de-genero-e-as-ameacas-a-democracia/\#prettyP hoto>. Acesso em: 15 nov. 2016.

BRASIL. Secretaria de Educação Fundamental. Parâmetros Curriculares Nacionais: terceiro e quarto ciclos: apresentação dos temas transversais. Brasília: MECSEF, 1998.

BRASIL. Conselho Nacional de Educação. Parecer $n^{\circ}$ 8, de 6 de março de 2012. Diretrizes Nacionais para $a$ Educação em Direitos Humanos. Diário Oficial [da] República Federativa do Brasil, Brasília, DF, 30 mai. 2012.

BRASIL. MEC. SEB. 2017. Base Nacional Comum Curricular. 2017. Brasília: MEC. Disponível em: <http://basenacionalcomum.mec.gov.br/images/BNCC_20dez_site.pdf.> Acesso em: 29 out. 2018.

CARA, Daniel. O programa “Escola sem Partido" quer uma escola sem educação. In: Ação Educativa Assessoria, Pesquisa e Informação (Org.). A ideologia do movimento Escola Sem Partido: 20 autores desmontam o discurso. São Paulo: Ação Educativa, 2016.

FREIRE, Paulo. A importância do ato de ler: em três artigos que se completam. São Paulo: Cortez; Autores Associados, 1982.

FREIRE, Paulo. Pedagogia da Autonomia: saberes necessários à prática educativa. 23 ed. Coleção Leitura. São Paulo: Paz e Terra, 1996.

FURLANI, Jimena. "Ideologia de Gênero"? Explicando as confusões teóricas presentes na cartilha. Versão Revisada 2016. Florianópolis: FAED, UDESC. Top afiliados Laboratório de Estudos de Gênero e Família, 2016.

GADOTTI, Moacir. A Escola Cidadã frente à Escola sem Partido. Disponível em: <http://paulofreire.org/noticias/500-a-escola-cidada-frente-a-escola-sem-partido>. Acesso em: 04 nov. 2017.

GIROUX, Henry. Teoria crítica e resistência em educação: para além das teorias da reprodução. Petrópolis, Vozes, 1986.

GIROX, Henry. Qual o papel da pedagogia crítica nos estudos de língua e de cultura? Entrevista com Henry Giroux. Revista Crítica de Ciências Sociais, n., 73, dez. 2005. p. 131-143.

GOMES, Joaquim Benedito Barbosa. Ação Afirmativa e Princípio Constitucional da lgualdade: o direito como instrumento de transformação social. A experiência dos EUA. Rio de Janeiro: Renovar, 2001.

GRAUPE, Mareli Eliane; SOUSA, Lúcia Aulete Búrigo de. Políticas públicas de gênero no campo da educação. In: GROSSI, Miriam Pillar; GARCIA, Olga Regina Zigelli; MAGRINI, Pedro Rosas. Especialização em Gênero e Diversidade na Escola - Livro II - Módulo II. Florianópolis: Copyright, 2015. Cap. 1. p. 72-110.

JUNQUEIRA, Rogério Diniz. A Pedagogia do Armário: heterossexismo e vigilância de gênero no cotidiano escolar. Educação On-Line (PUCRJ), v. 10, p. 64-83, 2012.

JUNQUEIRA, Rogério Diniz. "Ideologia de gênero": um dispositivo retórico de uma ofensiva antifeminista. In: DIAS, Alfrâncio F; SANTOS, Elza F; CRUZ, Maria Helena S. (Orgs.). Gênero e sexualidades: entre invenções e desarticulações. Aracaju: Editora IFS, 2017.

LIONÇO, Tatiana; DINIZ, Débora. Qual a diversidade sexual dos livros didáticos brasileiros? In: LIONÇO, 
GÊNERO E SEXUALIDADE: concepções e discussões acerca da educaçãoVIGANO, S. M. M.; LAFFIN, M. H. L. F.

Tatiana; DINIZ, Débora (Org.). Homofobia e educação: um desafio ao silêncio. Brasília: Letras Livres: Ed. UnB, 2009. p. 09-14.

LOURO, Guacira Lopes. O corpo educado: pedagogias da sexualidade. Tradução dos artigos: Tomaz Tadeu da Silva. 2.ed. Belo Horizonte: Autêntica, 2000.

LOURO, Guacira Lopes. Gênero, sexualidade e educação: das afinidades políticas as tensões teórico-metodológicas. Educação em Revista. Belo Horizonte: n. 46. dez. 2007. p. 201-218.

MOTTA, Flávia de Mattos. Gênero, sexualidade e educação. In: SARTORI, Ari José; BRITO,Néli Suzana (Org.). Gênero na educação: espaço para a diversidade. 2 ed. Florianópolis: Genus, 2006. p. 48-63.

OLIVEIRA, Ivanilde Apoluceno de. Contribuições da Educação de Paulo Freire para a Gênese da Interculturalidade no Brasil. In: VIII Colóquio Internacional Paulo Freire Educação como Prática da Liberdade: saberes, vivências e (re) leituras em Paulo Freire. Recife, UFPE, set 2013.

PIOVESAN, Flávia. Poder Judiciário. Caderno de Direito Constitucional: Direitos Humanos e o Direito Constitucional Internacional. V. 5. Escola da Magistratura do Tribunal Regional Federal da 4 a região EMAGIS - Rio Grande do Sul, 2006. Disponível em:

$<$ http://www.dhnet.org.br/direitos/militantes/flaviapiovesan/piovesan_dh_direito_constitucional.pdf $>$. Acesso em: 06 out. 2017.

SAFFIOTI, Heleieth. Gênero patriarcado violência. São Paulo: Expressão Popular, 2015.

SCALA, Jorge. Ideologia de Gênero: o neototalitarismo e a morte da família. 2. ed. Trad. Lyège Carvalho. São Paulo: Katechesis, 2015. 
ISSN 1983-1579

Doi: 10.22478/ufpb.1983-1579.2019v12n1.38670

http://periodicos.ufpb.br/ojs2/index.php

Recebido em: 08/11/2018

Alterações recebida em: 27/12/2018

Aceito em: 11/01/2019

Publicado em: 02/03/2019 